growth had disappeared and the growth was manifestly smaller. He returned to work on this date, and except for the fortnight referred to above has worked uninterruptedly since. The injections have been given in the afternoon, and he has been fit for work the next morning. Now, one and a half years after treatment was begun, there is no sign of recurrence, his general health is excellent, his weight has increased slightly (13 st. $7 \mathrm{lb}$.), and his monthly injection (5 minims) causes little general reaction.

It will be conceded, I think, that (1) the growth was, as evidenced by the rapidity of recurrence, of a high degree of malignancy ; (2) the action of the toxins is not due merely to local necrosis-shrinking of the growth was discernible before any injection was made into the tumour ; (3) a certain degree of immunity is acquired, so that a dose of 15 minims can be safely administered-a dose of 10 minims can be given regularly for several weeks; (4) the treatment can be carried out at the surgery or in the ont-patient department--the patient should be under supervision for four hours after each injection. It is desirable that the general health should be attended to during the treatment. An overdose produces its most obvious effects on the cardio-vascular and nervous systems.

The perfect ablation of a malignant growth is probably never achieved by surgery; the perfect result so often obtained is conceivably due to the setting free in the wound of large quantities of "protective" substances. Twenty years ago malignant growths were removed by comparatively imperfect methods, and yet a certain proportion had no recurrence. There seems no reasonable doubt that in such cases portions of growth were left, or at least tainted glands and lymphatics; we ought to be astonished that any cures were effected, unless we invoke some (as yet) unknown factor.

It seems reasonable to conceive of malignancy arising from lack or excess of some internal secretion, and that Coley's fluid provokes the laggard secretory organ to renewed activity or restrains the exuberance of the faulty gland. It certainly is disappointing that the enormous mass of research work during the last ten years is a literature chiefly of destructive criticism.

This is, I believe, the first recorded case in this country in which Coley's fluid has achieved the cure of a melanotic sarcoma. In America Dr. Coley says a colleague reports a similar case which has remained well for ten years.

Leeds.

\section{A CASE OF A SWALLOWED FORK.}

By Robert W. Willcocks, B.A. Cantar., M.R.C.S. Eng. L.R.C.P. LOND.

WHILE acting as a locum-tenent for Mr. P. G. Laver at Colchester I was called to a house about three and a half miles out to see a woman who was said to have swallowed a fork. I arrived about half an hour after the accident to find her lying on the floor in a state of collapse and evidently in great pain. On putting my finger down her throat, I was just able to feel, at the base of the tongue, what appeared to be the four tips of the prongs on a fork. The prongs were lying tightly against the root of the tongue, so that breathing and speaking were much impeded. Any manipulation while she was in the upright position only tended to push the fork farther down, so with the help of her husband I hung the woman over the side of a table with her head on the floor. I was then able, after about three minutes, to work the fork far enough downwards (I refer to the woman's position) to get a good grip of it and pull it ont. Even when a good grip was obtained it seemed to be held very tightly, owing, I suppose, to the contraction of the cesophagus round the thin part of the bandle.

After removal the woman recovered rapidly, and was able to tell me that she was about four months pregnant, and in the habit of using the handle of a fork for tickling the back of her throat to induce vomiting, as until that had taken place she was unable to enjoy her breakfast, and it was while doing this that the fork had somehow slipped down. It was an ordinary, large-sized, metal table fork, measuring 8 inches in length and 1 inch across the widest part of the handle and prongs.

Roehampton:

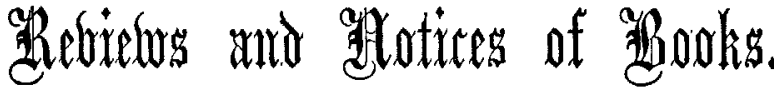

Tuberculous Diseases of Bones and Joints: Their Pathology, Symptoms, and Treatment. By Sir W. WATson CHEYNE, C.B., F.R.S., F.R.C.S. Fng., D.Sc. Oxon., LT.D. Edin. Professor of Clinical Surgery at King's College Hospital ; Senior Surgeon to King's College Hospital ; Consulting Surgeon to Paddington Green Children's Hospital. Second edition. Oxford University Press: Henry Frowde and Hodder and Stoughton. 1911. Pp. 404. Price 16s. net.

ONE of the most striking effects of the improvement in the general constitutional treatment of tuberculosis is the avoidance or postponement of resection or other operative interference with tuberculous joints. More reliance is now placed on rest of the joint in a suitable position, and signs are not wanting that this tendency to avoid operation may increase in the future. Sir Watson Cheyne in this new edition of his well-known work points out that the prognosis of surgical tuberculosis was formerly much more gloomy than at the present time, and that this is due to the present method of treatment which is more "expectant"; but he considers that conservative treatment may be overdone, and in this edition he has striven to hit the happy mean between too great haste and too much delay in operating:

The earlier chapters deal with the gross and minute changes occurring in tuberculosis of the synovial membranes, bones, and cartilage; these are well illustrated. In the chapter on the connexion of injuries with the deposit of tubercle in a joint or bone he expresses the opinion that the injury acts by interfering with the local protective mechanism. He shows by statistics that in children under the age of 10 years the relative proportion of male and female cases is practically the same, whether a history of trauma is present or not, but above this age there is an increased difference between males and females of 28 per cent. This argument is practically conclusive that injury is a factor in the production of tuberculosis of bones and joints.

The subject of treatment is dealt with fully. The climate most suitable for these forms of tuberculosis must depend in a great measure on the patient. He must have plenty of pure air, and the choice has to be made between a somewhat high inland situation, such as a Yorkshire farmhouse in summer and Devonshire in winter on the one hand, and a seaside town on the other. As to the question of operative treatment, the author's views may be summed up as follows: Operative treatment is desirable in the following caseswhen chronic suppuration has occurred; when, at an early stage, the disease is localised to one part of the synovial membrane or bone; when, in later stages, there is a deposit in the bone, with general synovial thickening; when, in cases of diffuse synovial thickening, expectant treatment has failed to arrest the progress of the disease; when a better functional result can be obtained by operation; when, in adults, deformities are present which can be remedied only by operation; sometimes when septic sinuses are present; sometimes when phthisis is present or when the general condition is such as to require removal of the disease ; in adults more frequently than in children; in the poor more often than in the rich. Subsequent chapters deal with the general principles of treatment, and then the chief joints are considered in turn, the signs and symptoms are described, and the treatment is detailed. The illustrations add distinctly to the value of this part.

The book has been rewritten and it now represents the best practice of the day, and all may accept without hesitation this exposition of the teaching of a surgeon and teacher who has done so much to raise the treatment of tuberculosis of bones and joints to its present level. 